\title{
Una teoría para la educación transdisciplinaria (Basada en el Manifiesto de Basarab Nicolescu)
}

\author{
A teory for the education transdisciplinary (Based on Manifesto Basarab Nicolescu) \\ María Luz Chávez Cáceres, Ph. D. (*)
}

"La transdisciplinariedad concierne (...) lo que está a la vez entre las disciplinas, a través de las diferentes disciplinas y más allá de toda disciplina. Su finalidad es la comprehensión del mundo presente en el cual uno de los imperativos es la unidad del conocimiento." Basarab Nicolescu, $1996^{1}$.

\section{RESUMEN}

Se hace un análisis de la propuesta de Nicolescu para la elaboración de una teoría de la educación desde la perspectiva de la transdisciplinariedad. Se pone énfasis en varias categorías que complementan muy bien la propuesta, a saber: El pensamiento complejo, la metodología transdisciplinar. Luego se desarrolla la perspectiva transdisciplinaria en relación a la educación matizando lo teórico con la realidad educativa misma.

Palabras clave: Teoría educativa, transdisciplinariedad, pensamiento complejo, metodología trasdiciplinar.

\section{SUMMARY}

An analysis of the proposal Nicolescu for developing a theory of education from the perspective of transdisciplinarity is made. Emphasis is placed into several categories that complement very well the proposal, namely: Thought complex, transdisciplinary methodology. transdisciplinary perspective in relation to education clarifying the theoretical with the same educational reality is then developed.

Keywords: Educational theory, transdisciplinarity, complex thinking, transdisciplinary methodology.

\footnotetext{
Docente Principal de la Universidad Nacional de Educación "Enrique Guzmán y Valle"
} 


\section{Introducción}

Todo parece indicar que la fragmentación del saber en múltiples disciplinas no es algo natural, sino el producto de limitaciones aprendidas de nuestra mente. En ese sentido el fisiólogo, neuro-psicólogo y filósofo ruso P. K. Anójin ${ }^{1,2}$, en sus escritos de mediados del siglo XX admitía que: "Es dificil situar en la historia de la civilización el momento preciso en que surgió la idea de la integridad del mundo. Es probable que en su primer intento por comprender el mundo, el hombre se haya enfrentado con la admirable armonía del todo, el "universo", y las partes aisladas. Sin embargo, el intelecto humano se relaciona constantemente con lo inmediato, con su ambiente y con los fenómenos de su "nicho" aislado, lo cual influyó de manera radical en el curso de la actividad cognoscitiva. Lo inmediato adquirió una gran importancia práctica para el funcionamiento de la actividad adaptativa del hombre, por tanto, el todo abstracto fue objeto de su actividad cognoscitiva posterior." (p. 48).

Tal planteamiento constituye la explicación del incesante auge que experimentó el desarrollo de las disciplinas individuales a lo largo de los siglos pasados, el mismo que parecía apuntar a la multiplicación de éstas hasta lo infinito. No obstante, en algún momento la situación empezó a mostrar sus límites, permitiendo el surgimiento de la tendencia contraria. De hecho -y como expresión de su vigencia- la relación, fusión e interconexión de las diversas disciplinas entre sí comienza a producirse cada vez con más frecuencia.

\section{Acerca de Pensamiento Complejo}

La tendencia representada por el paradigma del pensamiento complejo, hoy en plena consolidación a nivel mundial, ha traído aparejada varios cambios empezando por una nueva forma de ver la realidad, entendida ésta como todo lo que existe en el universo y, comprendido igualmente, el conjunto de las relaciones internas y externas que caracterizan a cada ser o ente integrante del mismo, independientemente de su estado o condición, de su ser concreto o abstracto, material o ideal, vivo o inerte.

1 Basarab Nicolescu, fundador y presidente del CIRET (Centre International de Recherches et Études Transdisciplinaires).

2 Anójin, P. K. (1987) Psicología y Filosofía de la Ciencia. Metodología del sistema funcional. México: Trillas. (Pág. 48)
En consecuencia, el pensamiento complejo no es algo que se imponga por moda o arbitrariedad de algún grupo de pensadores "con autoridad o prestigio". El pensamiento complejo constituye un paradigma de pensamiento que surge de la necesidad de adoptar una nueva lógica, una nueva visión y una nueva forma de establecer relaciones en el abordaje del conocimiento del mundo, de la sociedad y del ser humano, a riesgo de no lograr la comprensión cabal de la realidad, ni de los procesos que aseguran y explican su existencia y permanencia, o de su interrelación, organización y complementación entre sí.

Por lógica y de manera natural, el pensamiento complejo tiene su correlato en una visión de la realidad (todo lo que existe, sea cual fuere su naturaleza o especificidad) como algo siempre complejo, cuyo conocimiento debe ser concebido como un proceso multifacético y pluridimensional, pudiendo ser éste, a la vez, entre otros, biológico, cerebral, espiritual, lógico, lingüístico, cultural, social, histórico, sin por ello perder su individualidad e identidad y estableciendo relaciones entre el ser, la sociedad, la vida y el mundo.

Resulta evidente que mientras se concebía el mundo y su realidad como una yuxtaposición de partes y elementos fácilmente desmontables, pasibles de simplificación y de aislamiento entre sí, el pensamiento simple pudo parecer suficiente y hasta idóneo para acercarse a la "verdad". Hoy, con el reconocimiento de que no existe realidad simple, desconectadas sus partes entre sí o de otras realidades, el pensamiento complejo aparece como la única forma de dar cuenta de la realidad y de su funcionamiento. Cualquier otro abordaje conduciría a la mutilación y al reduccionismo. Sin embargo, advertimos acerca del peligro de caer en extremos. Como afirma Morin (1997): "No se trata de abandonar los principios de la ciencia clásica, orden, separabilidad, lógica, sino de integrarlos en un esquema que sea al mismo tiempo más amplio y más rico ${ }^{3} . "$

$\mathrm{Y}$ es Morin, precisamente, uno de los pensadores contemporáneos que con mayor rigor ha sistematizado y descrito la noción de pensamiento complejo. Con este término Morin se refiere a la capacidad de interconectar distintas dimensiones de la realidad o de los fenómenos u objetos del conocimiento existentes en ella. Morin señala que el ser humano, ante la presencia de hechos u objetos vistos como multidimensionales,

3 Morin, E. (2004). Introducción al pensamiento complejo. Barcelona: Gedisa 
interactivos y con componentes aleatorios o azarosos, se ve en la necesidad de desarrollar una estrategia de pensamiento acorde a la nueva visión de la realidad.

Así, esta nueva forma de ver la realidad, de manera natural y consecuente, promueve el uso de un enfoque transdisciplinario y holístico a la hora de analizarla, sin por ello abandonar la noción de las partes constituyentes del todo.

Consecuentemente, tras admitir que la realidad del mundo en que vivimos se caracteriza principalmente por la complejidad manifiesta de sus interconexiones a nivel global -donde todos los fenómenos existentes, cualquiera sea su naturaleza, resultan recíprocamente interdependientes- solo resta reconocer que, junto con el pensamiento complejo y la visión de conjunto para enfocar la realidad compleja, se debe considerar a la transdisciplinariedad conceptual y metodológica como la forma idónea para abordar su conocimiento.

\section{La Metodología Transdisciplinar}

Basarab Nicolescu ${ }^{4}$, uno de los grandes promotores del movimiento mundial por la transdisciplinariedad, en su ponencia leída en el II Congreso Internacional de Educación, Complejidad y Transdisciplinariedad, realizado en La Paz - Bolivia en octubre de 2012, titulada Dimensión espiritual de la democracia ¿Utopía o necesidad?, afirma categóricamente que el logro más importante de la transdisciplinariedad en la actualidad es, por supuesto, la formulación de la metodología de la transdisciplinariedad, sin la cual ésta sería por completo inaplicable y que nosotros rescatamos aquí, pues sirve a nuestros propósitos para el sustento epistemológico de lo que debiera ser una educación transdisciplinaria.

Esta metodología se basa en tres axiomas que, en conjunto, explican la esencia de la transdisciplinariedad y que son los siguientes:

1. El axioma ontológico, por el que se reconoce la existencia de diferentes niveles de realidad del objeto, $\mathrm{y}$, en consecuencia, distintos niveles de realidad del sujeto.

2. El axioma lógico, referido a que el paso de un nivel de realidad a otro está asegurado por la lógica del tercero incluido ( $\mathrm{T}$ ).

3. El axioma epistemológico, que da cuenta de que la estructura de la totalidad de los niveles de realidad es una estructura compleja, donde cada

4 Nicolescu, B. (1996) La transdisciplinariedad. Mani fiesto. Mónaco: Rocher. nivel es lo que es, debido a que todos los niveles existen al mismo tiempo.

Punto de partida muy importante para el presente análisis son asimismo las precisiones conceptuales que nos evitará el riesgo de caer en malentendidos. Nicolescu en el Manifiesto ${ }^{5}$ destaca que: "La disciplinariedad, la pluridisciplinariedad, la interdisciplinariedad y la transdisciplinariedad son las cuatro flechas de un solo y mismo arco: el del conocimiento." (p.37)

Corresponde dejar en claro que la transdisciplinariedad posee distinta naturaleza de aquella de la disciplinariedad en cualquiera de sus formas (multi, inter o pluridisciplinariedad), siendo finalidad última de la transdisciplinariedad la comprensión de la realidad del mundo en toda su complejidad, lo cual sería imposible de alcanzar mediante la investigación disciplinaria, por ambicioso y completo que fuera su diseño. No se trata, pues, de la búsqueda del conocimiento por el conocimiento mismo, o del conocimiento de fenómenos aislados (separados, uno por uno), sea cual fuere la disciplina o conjunto de disciplinas, aun actuando ellas de manera interconectada, puesto que es distinto el fin perseguido.

Deberá tenerse en cuenta que la finalidad primordial de la investigación disciplinaria es y será siempre la obtención de resultados (verdades) relevantes para cada disciplina en particular, de modo que el hallazgo, en primer lugar, estará orientado a incrementar el caudal de conocimientos propio del respectivo campo de estudio.

Es importante tener en cuenta la advertencia de Nicolescu acerca del peligro de confundir transdisciplinariedad con interdisciplinariedad y más aún, con la pluridisciplinariedad. Ello se explica nos dice- "por el hecho de que las tres desbordan las disciplinas. Esta confusión es muy nociva en la medida que oculta las finalidades diferentes de esas tres nuevas perspectivas."

En opinión nuestra, lo expresado anteriormente no debe entenderse como el advenimiento inminente de una ciencia especial o superciencia denominada ciencia transdisciplinar que vendría a anular la utilidad y vigencia de las disciplinas. Por el contrario, las disciplinas y las inter-disciplinas, aún las de reciente creación, seguirán su evolución y desarrollo. Después

5 Nicolescu, B. (1996) La transdisciplinariedad. Manifiesto. Mónaco: Rocher. 
de todo, como sugiere Nicolescu, resulta evidente que sin disciplinas la transdisciplinariedad sería un conjunto vacío.

Para nosotros, la transdisplinaridad reside y comienza en la actitud del científico (de cualquier disciplina) para captar la realidad compleja y, dentro de ella, identificar y delimitar el problema de investigación con visión de conjunto y pensamiento complejo (percepción problémica). Por ejemplo, los educadores dedicados a la investigación transdisciplinaria no necesitarán renunciar a sus respectivas especialidades ni adquirir un título profesional distinto al que ostentan. Bastará con que adopten una actitud investigativa de nuevo tipo, enmarcada en el paradigma transdisciplinar y el pensamiento complejo para que, luego de identificado correctamente un problema educativo -que nunca será simple, sino complejo- puedan emprender y llevar a cabo con éxito la investigación pedagógica propuesta. La alianza con las disciplinas viene después de esta fase. Sin perder de vista el problema y sólo en función de éste, se acudirá a la experticia, métodos y demás parafernalia investigativa proveniente de otras disciplinas. Es así como se deberán conformar los equipos transdisciplinares para la investigación de un problema complejo, mas no a priori, sino como consecuencia de la complejidad del problema una vez que esta complejidad se torna evidente, es decir, que se ha revelado y puesto de manifiesto. Lo expresado se confirma con las palabras de Nicolescu: "Como en el caso de la disciplinariedad, la investigación transdisciplinaria no es antagónica sino complementaria de la investigación pluri e interdisciplinaria."

\section{La Transdisciplinariedad en Educación}

La exploración e interpretación de los textos que siguen a continuación reviste para nosotros la mayor importancia, por cuanto contiene la explicación de Nicolescua cómo se concibe la realidad transdisciplinar, de modo que nos permita comprender la esencia de una teoría de la educación transdisciplinaria.

Iniciaremos este esfuerzo con la reflexión sugerida por Nicolescu sobre la frase que apertura el apartado del Manifiesto titulado "Transdisciplinariedad y unidad abierta al mundo" (p. 37): "La visión transdisciplinaria nos propone considerar una Realidad multi-dimensional, estructurada a varios niveles, que remplaza la Realidad unidimensional, a un solo nivel, del pensamiento clásico”.
De hecho, aquí Nicolescu nos anuncia un trato distinto de la realidad; nos invita a compartir una visión "volumétrica" de la misma: no unidimensional, no a un solo nivel, no enmarcada en el pensamiento clásico. Por nuestra parte pondremos el acento en aquello que consideramos sin duda uno de los aportes más significativos de Nicolescu a la teoría y metodología de la transdisciplinariedad. Se trata del sentido que él imprime al concepto "realidad" y la forma cómo explica el otro concepto asociado: "niveles de realidad". De manera taxativa Nicolescu distingue las palabras "real" de "realidad". Para él real designa lo que la cosa es, mientras que el término realidad se vincula con toda propiedad a lo que el objeto muestra de sí, de la manera como puede ser -y de hecho espercibido por el sujeto cognoscente. El concepto nivel de Realidad resulta fundamental para entender e interpretar el siguiente pasaje del Manifiesto de la Transdisciplinariedad:

"Un nuevo principio de Relatividad emerge de la coexistencia entre la pluralidad compleja y la unidad abierta: ningún nivel de Realidad constituye un lugar privilegiado donde se puedan comprender todos los otros niveles de Realidad. Un nivel de Realidad es lo que es porque todos los otros niveles existen a la vez. (...) Y cuando nuestra mirada sobre el mundo cambia, el mundo cambia".

Se pone de relieve aquí la vivencia de la realidad por el sujeto cognoscente. Quien tiene la vivencia de un nivel, sólo puede dar cuenta de ese nivel. El nivel anterior (o inferior) es historia y el posterior (o superior) aún no ha sido vivido, aún no ha acontecido para el sujeto cognoscente.

"Existe, ciertamente, una coherencia del conjunto de los niveles de Realidad, pero esta coherencia está orientada: una flecha está asociada a toda transmisión de la información de un nivel a otro. Como consecuencia, la coherencia, si está limitada a los solos niveles de Realidad, se detiene al nivel más "alto" y al nivel más "bajo." Para que la coherencia continúe más allá de estos dos niveles límites, para que exista una unidad abierta, es necesario considerar que el conjunto de los niveles de Realidad se prolonga por una zona de no-resistencia a nuestras experiencias, representaciones, descripciones, imágenes o formalizaciones matemáticas. (...) Pero estos dos niveles siendo diferentes, la transparencia absoluta aparece como un velo, desde el punto de vista de nuestras experiencias, representaciones, descripciones, imágenes oformulaciones matemáticas. En efecto, la unidad abierta del mundo implica que 
lo que es "abajo" es como lo que es "arriba." El isomorfismo entre lo "alto" y lo "bajo" es restablecido por la zona de no- resistencia". (Pág. 43)

En este pasaje Nicolescu, a nuestro entender, describe como zona de la transparencia, el espacio (teórico o figurado) que existe entre dos asas (bucles) de una espiral dialéctica, sin cuya presencia la espiral no sería tal, sino tan sólo un círculo vicioso, plano, chato, idéntico a sí mismo, sin progreso ni desarrollo, sin pasado ni futuro. Sin embargo, nos parece importante hacer notar, siempre guiados por la teoría esbozada, que esta zona de la transparencia desempeña, asimismo, el rol de punto crítico que marca el paso de un nivel a otro y donde se resuelve la contradicción de A y no-A, por y en presencia del tercero incluido $\mathrm{T}$, como se expondrá más adelante.

"La unidad de los niveles de Realidad y su correspondiente zona complementaria de noresistencia constituye lo que llamamos el Objeto Transdisciplinario".

Nicolescu se refiere aquí al producto final de la realidad estudiada, la cual se mostraría en su plenitud cuando se considera al objeto complejo y completo en toda su evolución. Se trataría del objeto real presente, con todas sus conexiones internas y externas, con su pasado, presente y futuro, íntimamente coligados e interdependientes.

"Los diferentes niveles de realidad del objeto son accesibles a nuestro conocimiento gracias a los diferentes niveles de realidad del sujeto".

Esta acotación nos parece particularmente importante para una teoría de la educación transdisciplinaria, desde que todo aprendizaje tiene como producto resultante algún tipo de conocimiento: (conceptual o declarativo, procedimental propiamente dicho, estratégico o condicional) ${ }^{6}$, lo que implica una adquisición progresiva, nivel tras nivel. De este modo, los seres humanos tomamos conocimiento de la realidad en la medida que nosotros mismos poseemos diferentes niveles de realidad y los ajustamos a la particularidad de cada nivel de realidad del objeto, integrando asimismo sus correspondientes zonas de la transparencia. Nicolescu afirma que "La unidad de los niveles de realidad del sujeto y su correspondiente zona complementaria de la no-resistencia constituye lo que llamamos Sujeto Transdisciplinario".

6 Monereo, C. y otros. (1994) Estrategias de enseñanza y aprendizaje. Barcelona: Graó. (pp. 99-124)
"La zona de la no-resistencia desempeña el papel de un tercer integrante entre el Sujeto y el Objeto, un término de interacción que permite la unificación del Sujeto y el Objeto transdisciplinario, conservando su diferencia. En lo siguiente voy a llamar a este término de interacción Tercer integrante Oculto. (...) El objeto transdisciplinario y sus niveles, el Sujeto transdisciplinario y sus niveles y el Tercer Integrante Oculto definen lo que es la trans-Realidad".

El texto transcrito contiene la descripción de la totalidad de elementos componentes de la espiral dialéctica de la realidad, como es concebida desde la teoría de la transdisciplinariedad. Aquí nos parece sumamente importante destacar que el término transrealidad, acuñado por Nicolescu y que desempeña un rol designante de una categoría dentro de la teoría del autor, en la práctica cotidiana y para el común de las personas es sólo equivalente al término simple de realidad.

En este punto consideramos pertinente recordar que la ciencia no inventa la realidad y los científicos o epistemólogos tampoco. Que una realidad pueda ser vista como objeto transdisciplinar, con todos sus niveles, zonas de no-resistencia incluidas, interconexiones extrínsecas e intrínsecas y demás particularidades, será posible sólo a los ojos atentos e informados de un Sujeto Transdisciplinario. Para el resto de seres humanos, para los sujetos comunes y corrientes, la realidad será simple, estará allí, muda, estática, sin movimiento, sin historia ni devenir y muy frecuentemente, sin explicación alguna del porque de su presencia, existencia y/o apariencia.

"Para obtener una imagen clara del sentido del tercero incluido, representemos los tres términos de la nueva lógica-A, no-Ay T-y sus dinamismos asociados, por un triángulo en el cual uno de los vértices se sitúa en un nivel de Realidad y los otros dos en otro nivel de Realidad. Si se permanece en un solo nivel de Realidad, toda manifestación aparece como una lucha entre dos elementos contradictorios (ejemplo: onda A y corpúsculo no-A). El tercer dinamismo, el del estado T, se ejerce a otro nivel de Realidad donde eso que aparece como desunido (onda o corpúsculo), es de hecho unido (quanton), y eso que aparece como contradictorio es percibido como no-contradictorio". (p.24)

La explicación anterior se aplica perfectamente a cualquier realidad que haya sido vista y concebida como transcompleja (con visión transdisciplinar y 
pensamiento complejo). A continuación y en calidad de propuesta, presentamos aquello que podría constituir una teoría transdisciplinaria general del aprendizaje, desde que explicaría todo tipo de aprendizaje, de cualquier ámbito de actividad humana: motor, intelectual, afectivo, laboral productivo, interpersonal, musical, artístico, entre otros. A manera de ilustración presentamos la propuesta aplicada a la adquisición de las habilidades motrices y deportivas.

Es evidente que "nadie nace sabiendo". El ser humano todo lo asimila, a partir de la capacidad de aprender con la que nace. Y, en efecto, la capacidad de aprender es natural en el sentido de que es parte del paquete genético con el que cada quien ha venido a este mundo. No obstante, sería un gran error pensar que la capacidad de aprender es la misma a lo largo de toda nuestra existencia. Ésta, como cualquier otra capacidad, se expande, se enriquece, crece, se desarrolla, se incrementa, o, a veces, se estanca, para luego retomar (o no) su ritmo de desarrollo anterior, todo ello en dependencia de cuánto, de qué manera, con qué frecuencia y para aprender qué, la utilicemos. Es decir, nacemos capaces, y gracias al aprendizaje devenimos en seres humanos hábiles y competentes. Y esto ocurre todo el tiempo, a lo largo de nuestra vida, utilizando la capacidad de aprender con la que hemos nacido.

La pregunta a ser planteada ahora sería: ¿Cómo adquirimos las habilidades motrices y/o deportivas? ¿Cómo las aprendemos? ¿Cuál es el proceso que nos convierte en hábiles motrices? Y, de existir tal proceso ¿Cómo trabaja y cuáles son sus elementos?

Para responder a estas interrogantes tomaremos la síntesis de un material ad hoc publicado en España hace algunos años.

"Destrezas, hábitos y habilidades, son los contenidos especificos y característicos de la educación física (...) En el proceso de su adquisición, destrezas, hábitos y habilidades se encuentran intimamente relacionadas entre sí conformando un verdadero sistema, siendo su base común la posesión de una determinada capacidad. (...) Su adquisición se desarrolla en forma de una espiral dialéctica. Completar un ciclo significa acceder a un nivel superior de maestría motriz y estar preparado para nuevos aprendizajes, cada vez de mayor complejidad. En todos los momentos de su vida el ser humano está construyendo destrezas, fijando hábitos, adquiriendo y cultivando habilidades". (p. 158)
Como se observa, destreza, hábito o habilidad no son entes tangibles, sino estadíos por los que pasa el aprendizaje, visto éste como un sistema de elementos eslabonado, donde la habilidad aprendida representa el resultado del funcionamiento de todo el sistema. Cada vez que se completa un asa o bucle, se completa un ciclo que se cierra sobre sí mismo, pero a distinto nivel. Cada vez que ello ocurre se alcanza un grado superior de dominio de lo aprendido. En el gráfico, asimismo, se aprecia la superposición de dos elementos del sistema (capacidad y habilidad) no obstante, esta superposición se da solo en teoría, pues cada elemento individualmente considerado representa un momento distinto de la ontogénesis motriz: el momento inicial y el momento final del proceso.

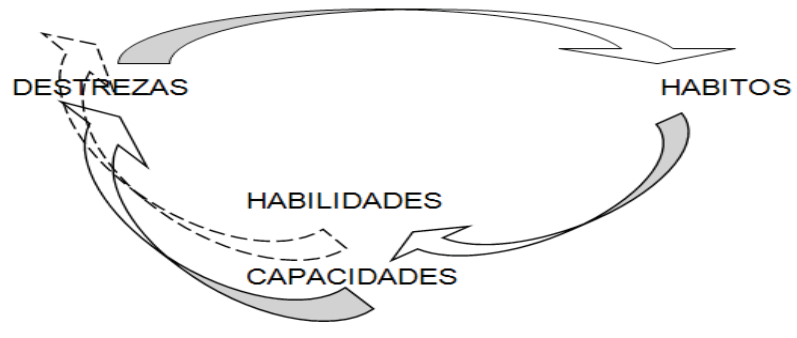

Aplicando la teoría de la transdisciplinariedad de Nicolescu al esquema presentado, tendríamos que A, es igual a DESTREZA; no-A, equivale a HÁBITO; y HABILIDAD es A y no-A al mismo tiempo. La HABILIDAD, siendo cualitativamente distinta de A y no-A, representa una síntesis natural de ambas porque viene de ellas y porque las tiene incorporadas en su esencia. La habilidad contiene la destreza en la medida que sólo es hábil quien ya ha adquirido el dominio de una destreza y ésta se encuentra perfectamente internalizada en el sujeto bajo la forma (o estadío) de hábito motor. La habilidad representa pues la conjunción simultánea de A, no-A y $\mathrm{T}$ en un mismo punto, aunque en un nivel distinto (superior) como veremos más adelante.

Se cumple así una importante especificación del modelo transdisciplinar, respecto del carácter conciliador de $\mathrm{T}$, contenido en el Manifiesto de Nicolescu:

"La lógica del tercero incluido es nocontradictoria, en el sentido en que el axioma de nocontradicción es perfectamente respetado, a condición de que se ensanche la noción de "verdadero" y "falso" de tal manera que las reglas de implicación lógica conciernen ya no dos términos ( A y no-A) sino tres términos ( $A$, no- $A$ y $T$ ), coexistiendo en el mismo momento del tiempo. Es una lógica formal, del mismo 
tenor que toda otra lógica formal: sus reglas se expresan por un formalismo matemático relativamente simple". (p.25).

Al tomar el ejemplo del ámbito de la educación física (o del movimiento) hemos querido simplemente facilitar la comprensión recurriendo a hechos asequibles. Al igual que las destrezas motoras pertenecientes a algún deporte o juego específico, existen destrezas motoras relacionadas con otras esferas de la actividad humana, como son las destrezas laborales requeridas en la producción de algún bien tangible: una mesa, una silla, un mueble, un zapato, una blusa, una canasta. Y, asimismo, destrezas, hábitos $\mathrm{y}$ habilidades intelectuales que nos permiten operar con los conceptos propios de diferentes campos del saber: matemática, física, química, biología; y destrezas, hábitos y habilidades propias de la inteligencia emocional, como aquellas que permiten el control de las emociones, de los impulsos, la manifestación (o no) de los sentimientos, entre otras.

Tratando el tema del aprendizaje en general surge la pregunta ¿cuándo y porqué aprende algo un ser humano? Es evidente que un aprendizaje tiene lugar cuando existe en el aprendiz una motivación intrínseca, aparte por supuesto del conocimiento previo suficiente y de las condiciones adecuadas. Una de las motivaciones es siempre la curiosidad natural del ser humano, seguida del asombro al percatarse de cómo funciona la realidad ante sus ojos, independientemente del nivel de realidad del objeto o del nivel de percepción del sujeto. Es así que todos estamos en capacidad de aprehender la realidad, por muy poco que ella se muestre, o por pequeño que sea el bagaje que se tenga acerca de la materia en cuestión. Todo dependerá del interés del sujeto. Naturalmente "más aprende el que más sabe" como reza el adagio popular y "sólo aprende el que presta atención y no se distrae", como aconsejan los buenos maestros de escuela primaria. Pero lo importante aquí es poner de relieve el carácter abierto de todo aprendizaje, de todo conocimiento y del proceso educativo en general. Son abiertos e infinitos en su evolución y desarrollo; bucle tras bucle, nivel tras nivel, su curso solo se detiene con la muerte.

Completada una fase, un bucle, un nivel, la ontogénesis humana se impone. Una vez que ha aprendido/conocido algo, el ser-humano-aprendiz está ávido y listo para emprender nuevos aprendizajes. Se cumple así una característica muy importante de la teoría transdisciplinar. Nicolescu, en el Manifiesto respecto al tema, dice que:

"Lo desconocido, lo inesperado y lo imprevisible en un momento dado de la Historia [del ser humano aprendiz] se transforma, con el tiempo, en conocido, esperado y previsible, pero simultáneamente nace una nueva forma de desconocido, de inesperado $y$ de imprevisible. La estructura gödeliana de la Naturaleza y del conocimiento garantiza la presencia permanente de lo desconocido, de lo inesperado y de lo imprevisible". (p.100)

El proceso del aprendizaje, asociado a la educación permanente del ser humano a lo largo de su existencia; es decir, desde que nace hasta que muere, se explica por la tendencia a la infinitud de la superposición de niveles:

"La lógica del tercero incluido es capaz de describir la coherencia entre los niveles de Realidad por el proceso iterativo que comprende las siguientes etapas: 1. Un par de contradictorios (A, no-A) situados a un cierto nivel de realidad está unificado por un estado $T$ situado a un nivel de Realidad inmediatamente vecino. 2. A su vez, este estado T está unido a un par de contradictorios (A', no-A') situado a su propio nivel; 3. El par de contradictorios (A', no-A') está a su vez unificado por un estado T' situado a un nivel diferente de Realidad inmediatamente vecino de él, donde se encuentra la terna ( $A^{\prime}$, no- $\left.A^{\prime}, T\right)$. El proceso iterativo continúa al infinito hasta el agotamiento de todos los niveles de Realidad conocidos o concebibles".

Corresponde ahora analizar la frase "Si se permanece en un solo nivel de Realidad, toda manifestación aparece como una lucha entre dos elementos contradictorios", contenida en una cita anterior (pág. 8 del presente documento). Veamos: ¿Se cumple esto en el ejemplo presentado? ¿De qué manera se evidencia? En efecto, se cumple en todos los casos y se comprueba cuando se selecciona para el análisis un par cualquiera de elementos contiguos.

Capacidad y destreza deportivas, por ejemplo, son pares contiguos y la vez contrarios en cuanto a su materialidad. La capacidad de aprender a nadar es potencial en el sujeto sano que sabe flotar; es decir, existe como posibilidad, mientras que la destreza para desplazarse a nado sobre la superficie del agua existe como realización concreta de alguien que ha aprendido a hacerlo. Otro par de contrarios serían la destreza y el hábito, puesto que ambos son mutuamente excluyentes y opuestos totales en cuanto a la participación de la conciencia durante 
su ejecución. Mientras que la destreza requiere de toda la atención consciente del sujeto para ser realizada óptimamente, el hábito, en el estadío de su máxima perfección, deviene en estereotipo dinámico, totalmente automatizado y no consciente. Finalmente, hábito y habilidad son asimismo contrarios. El hábito puro y bien logrado responde a señales asociadas tipo estímulo-respuesta, del mismo tipo no-consciente de las respuestas naturales instintivas, mientras que las habilidades corresponden a respuestas oportunas, estratégicas y adecuadas a situaciones perfectamente reconocidas por la conciencia del sujeto actuante. Este comportamiento de los pares opuestos confirma la aseveración de Nicolescu:

"Un solo y mismo nivel de Realidad no puede sino engendrar oposiciones antagonistas. Él es, por su propia naturaleza, auto-destructor, si está separado completamente de todos los otros niveles de Realidad". (p.25)

Esto último es perfectamente entendible desde que el tercer elemento $\mathrm{T}$ (conciliador) siempre se encontrará en el "entrepiso" del nivel siguiente, situado en la misma línea de su antecedente, el cual a su vez se encuentra en la misma línea, pero en el "entre-piso" del nivel inferior. En nuestro ejemplo, el punto donde confluyen y se superponen capacidad y habilidad es el vértice que corresponde al tercero incluido T, y si bien cada cual representa la unidad, no son ajenos a la contradicción. Perteneciendo a la realidad presente del sujeto aprendiz (desde que son una y misma cosa), conceptualmente están separados por la zona de no-resistencia que los sitúa en niveles de Realidad distintos ("arriba" y "abajo"). No obstante, visto el binomio capacidad/habilidad como un todo, una unidad donde coexisten A, no-A y T a la vez, este binomio representa el futuro y el pasado motriz del sujeto al mismo tiempo. Se trata pues de una sola cosa, de una realidad que aparece como simple y elemental a los ojos de un Sujeto no-transdisciplinario: su desempeño motriz actual y nada más que eso.

Ante la pregunta que se plantea a sí mismo el autor: ¿Cómo podemos ir, a nuestro entender, de un nivel de realidad a otro nivel de realidad? La respuesta no se deja esperar, pero está precedida por la explicación de que son los hábitos de nuestra mente los mayores impedimentos para captar la realidad. El lastre principal estaría en la forma cómo elaboramos nuestros pensamientos, guiados por una lógica clásica que no tolera contradicciones y donde uno de sus axiomas es el tercero excluido, por el cual no existe un tercer término ( $\mathrm{T}$ ) que pudiera ser, a la vez, A y
no-A. La respuesta a la pregunta planteada es dada por Nicolescu de la siguiente manera.

"Dos niveles adyacentes se unen por la lógica del tercero incluido, en el sentido de que el estado Tpresente a un cierto nivel está unido a un par de contradictorios ( $A$, no-A) del nivel inmediatamente vecino. El estado Topera la unificación de los contradictorios $A$ y no-A pero esta unificación se opera a un nivel diferente de ese donde están situados A y no-A. El axioma de no contradicción es respetado en este proceso". ( $p$. 39)

En el ejemplo que nos sirvió de ilustración, tomado del ámbito de la educación física y el deporte (o, mejor dicho, de la educación de la motricidad o educación del movimiento), la habilidad, al ser el resultado del funcionamiento del sistema arriba representado, tiene como producto final el logro de un nivel superior de dominio. En realidad, la diferencia entre capacidad y habilidad es básicamente conceptual, de modo que considerar que algo sea una u otra cosa, dependerá sobre todo del punto de vista del observador. Por cuanto ambos fenómenos, capacidad y habilidad, pertenecen al presente de cada persona resulta frecuente su confusión a los ojos de un sujeto no transdisciplinario. Así, toda capacidad puede ser vista como producto de un aprendizaje anterior y considerada una habilidad lograda como resultado de la culminación del asa o bucle que viene de completarse; y, a su vez, toda habilidad, que sabemos es el producto final del proceso aprendizaje, podría ser catalogada como una capacidad, si ésta es asumida y considerada como conocimiento previo y punto de partida para nuevos aprendizajes. No obstante, corresponde aquí precisar los conceptos con mayor exactitud, a fin de evitar confusiones.

Recurriendo al Diccionario de la RAE tenemos que CAPACIDAD significa: "Aptitud, talento, cualidad que dispone a alguien para el buen ejercicio de algo"; es decir, el término resulta ser sinónimo de potencialidad de cara al futuro, no de logro alguno. Por otro lado, una definición exacta y adecuada del concepto COMPETENCIA sería aquella que la equipara con una macro-habilidad, en el sentido de constituir una habilidad compleja. Tener en consideración tal diferencia será de gran utilidad cuando analicemos y tomemos conciencia de las consecuencias que acarrea la falta de claridad epistemológica en el momento de la toma de decisiones gubernamentales, sobre todo, en materia de educación. 
En el año 2009 el MINEDU ${ }^{7}$ puso en vigencia un $\mathrm{DCN}^{8}$ "por competencias". Pero ¿qué ocurrió? Deducimos que por imprecisión lingüística o falta de rigor conceptual de los autores, se colocó a las competencias como el elemento macro (válido para dos o tres años de estudios), obligando a los docentes que laboran en las instituciones públicas y privadas del país a "enseñar" CAPACIDADES en el aula de clase, como si se tratara de un elemento micro, enseñable en unas cuantas sesiones de aprendizaje. Lo cual, como veremos, trajo consecuencias asociadas. Los docentes de todas las modalidades y niveles educativos bajo supervisión del MINEDU, debido a este diseño curricular equivocado, están obligados a evaluar CAPACIDADES al final de cada período lectivo, mediante la ilógica disgregación (a contra sentido) de tres componentes que habrían intervenido en el proceso educativo: conocimientos, procedimientos, actitudes.

Al respecto Nicolescu, en el Manifiesto de la Transdisciplinariedad nos previene contra confusiones, precisando que:

"En el mundo de los niveles de Realidad per se, lo que es "arriba" es como lo que es "abajo" pero lo que es abajo no es como lo que es arriba. La materia más fina penetra la materia más gruesa, como la materia cuántica penetra la materia macrofísica, pero la afirmación recíproca no es verdadera. Los grados de materialidad inducen una flecha de orientación de la transmisión de la información de un nivel a otro. En ese sentido, en lo anteriormente dicho "lo que es abajo no es como lo que es arriba," las palabras "arriba" y "abajo" no tienen otra significación (espacial o moral) que aquella, topológica, asociada a la flecha de la transmisión de la información". (pág. 41)

Como se desprende de la aplicación de la teoría transdisciplinar al caso del DCN peruano actual, constituye una gruesa transgresión conceptual y epistemológica la inversión de los niveles. Acorde a la lógica propuesta, la habilidad/competencia lograda en el proceso enseñanza aprendizaje contiene a la capacidad y la trasciende, la penetra, desde que ésta última constituye su origen y representa su base fundante, de la misma manera que "La materia más fina penetra la materia más gruesa, como la materia cuántica penetra la materia macrofísica, pero la afirmación recíproca no es verdadera", porque el sentido de "la flecha de orientación de la transmisión

7 Ministerio de Educación (Perú).

8 Diseño Curricular Nacional. Disponible en http://www. minedu.gob.pe/ de la información de un nivel a otro" se lo impide. La capacidad, siendo primigenia, es decir pre-existente, representa la materia más gruesa y pertenece al nivel de "abajo"; mientras que la competencia, al constituir el refinado producto del aprendizaje, representa la materia más fina y pertenece al nivel de "arriba". En consecuencia, una habilidad/competencia no puede arbitrariamente ser descompuesta en "capacidades", desde que su sola pretensión configura un imposible, como lo sería el intentar invertir la flecha del tiempo. El presente contiene al pasado, puesto que es su antecedente inmediato, pero el presente no podría contener el futuro, habida cuenta de que éste aún no existe y que su materialización se encuentra sujeta a diversos grados de incertidumbre. Se cumple así lo manifestado por Nicolescu en la cita precedente: "la afirmación recíproca NO es verdadera".

Por otra parte, y no obstante reconocer la importancia del fundamento epistemológico transdisciplinario, pensamos que para que se realice una reforma educativa verdadera, será necesario ir más allá, abocarse a preparar propuestas que transformen las prácticas de los docentes, en cada área, en cada espacio curricular, en todos los niveles educativos, basadas en nuevas formas de actuación docente en las aulas, y otro tanto se tendría que hacer con los contenidos educativos. Urge, en consecuencia, seleccionar/diseñar nuevos contenidos (macrocontenidos de nuevo tipo y no simples temas de clase) coherentes con una concepción transdisciplinar del mundo y de la educación, de otro modo las buenas intenciones quedarán solo en ello y la educación nacional, tal cual la conocemos hoy en día, no avanzará ni podrá experimentar cambio significativo alguno.

El problema así planteado es eminentemente social, aparte de pedagógico, reclamando de la institución escolar, de sus autoridades y de sus docentes, una solución que deviene en impostergable. Frente a ello numerosos educadores en distintas latitudes del planeta se han puesto a la vanguardia del movimiento complejizante y transdisciplinar en educación y están proponiendo la urgente y necesaria redefinición del rol de la escuela y de los contenidos que ofrece. En esa misma línea el educador catalán Antoni Zabala (1999), refiriéndose a los nuevos contenidos escolares, planteaba:

"Si afirmamos que la realidad es el objeto de estudio y que ésta es global u holística, parece que los contenidos (...) necesarios para hacerle frente tendrían que provenir de un saber que pudiera dar respuestas globales y complejas a problemas que son 
globales y complejos. Una ciencia que dispusiera de instrumentos interpretativos y metodológicos, con un cuerpo teórico que permitiera abordar los problemas de la realidad de una forma global. O sea, una ciencia de carácter transdisciplinar que se planteara el estudio de la realidad desde su totalidad". (p.55)

En concordancia con lo expresado, diremos que la realidad del mundo en que vivimos es un todo polisistémico y este todo polisistémico, que constituye la naturaleza global, nos impele a adoptar una visión transdisciplinaria para poder captar la riqueza de la interacción entre los diferentes subsistemas que conforman la realidad. En la institución escolar ya no podemos seguir encargando a cada disciplina una parte o un aspecto de su estudio, agrupando luego los resultados para dar solución a un determinado problema. Se debe superar el uso simple de la multidisciplinariedad y de la interdisciplinariedad. Este esfuerzo intelectual exige proceder respetando la integralidad de los objetos de estudio, al margen de su pertenencia al campo de diferentes disciplinas, a fin de lograr la integración del saber en un todo coherente y lógico. Viene a acotación lo expresado por Martínez (2003) al respecto: "Esta lógica sería una lógica privilegiada en el estudio de las realidades complejas, privilegiada en el sentido de que nos permite cruzar los linderos de las diferentes áreas del conocimiento en forma coherente y nos habilita para crear imágenes de la realidad más completas, más integradas y, por consiguiente, también más verdaderas".

\section{REFERENCIAS BIBLIOGRÁFICAS}

1. Anójin, P. (1987). Psicología y Filosofía de la Ciencia. Metodología del sistema funcional. México: Trillas.

2. Chávez Cáceres, M. (1998). Metodología participativa en la educación física escolar. En la obra colectiva Educación fisica escolar y deporte de alto rendimiento. Las Palmas de Gran Canaria España: ACCAFIDE.

3. Chávez Cáceres, M. (2006). De las capacidades a las habilidades motrices: desde un enfoque, sistémico, holístico y transdisciplinar. En Revista Investigación Educativa. Vol. $10 \quad \mathrm{~N}^{\mathrm{o}} 18$ / JulioDiciembre 2006. Lima: UNMSM.

4. Martínez, M. (2003). Transdisciplinariedad y Lógica Dialéctica. Un enfoque para la complejidad del mundo actual. Publicación electrónica. Recuperado 16-02-2014 http://prof.usb.ve/ miguelm/transdiscylogicadialectica.html.

5. Monereo, C. y otros. (1994). Estrategias de enseñanza y aprendizaje. Formación del profesorado y aplicación en la escuela. Barcelona: Graó.

6. Nicolescu, B. (1996). La transdisciplinariedad. Manifiesto. Mónaco: Rocher.

7. Zabala, A. (1999). Enfoque globalizador $y$ pensamiento complejo. Una respuesta para la comprensión e intervención en la realidad. Barcelona: Graó. 